\title{
Low-profile Slotted SIW Cavity Backed Antenna for Frequency Agility
}

\author{
Fakher SBOUI ${ }^{1}$, Jan MACHAC ${ }^{2}$, Ali GHARSALLAH ${ }^{1}$ \\ ${ }^{1}$ Dept. of Physics, Microwave Electronics Research Laboratory, Faculty of Sciences of Tunis, \\ University of Tunis El Manar, Tunis 2092, Tunisia \\ ${ }^{2}$ Dept. of Electromagnetic Field, Czech Technical University in Prague, Technicka 2, 16627 Prague 6, Czech Republic
}

Fakher.sb@gmail.com, machac@fel.cvut.cz, ali.gharsallah@fst.utm.tn

Submitted November 27, 2018 / Accepted April 30, 2019

\begin{abstract}
The agile frequency antennas are widely used for wireless communication systems. This paper studies and designs a low-profile SIW antenna radiating from a circular slot graved in the ground plane, with the ability of alternating the frequency. The antenna is intentionally designed within a range of $1.8 \mathrm{GHz}$ to $2.18 \mathrm{GHz}$ obtained by varying the DC bias voltages from 0 to $26 \mathrm{~V}$, which is able to cover the GSM1800, the LTE, and the UMTS wireless standards. The tuning technique consists in the integration of two varactor diodes across the circular slot. A prototype was manufactured, and the experiment results correspond well to those of the simulations.
\end{abstract}

\section{Keywords}

Substrate integrated waveguide, frequency reconfigurable antenna, cavity backed antenna

\section{Introduction}

Reconfigurable antennas have received a special attention for their outstanding applications in wireless communication systems thanks to their selectable and fundamental features [1-4]. Frequency tunable antennas still attract many researchers' attention and many tuning techniques have been reported to obtain the agility. Some techniques have used "intelligent" substrates including ferromagnetic substrates and liquid crystal materials [5], [6]. A number of other works employs active localized components, such as PIN diodes [7], [8], MEMS [9] and exclusively varactor diodes [10] which are easy to integrate with planar structures and present a continuous and great agility. Many varactor-loaded frequency agile antennas have been presented in the literature in the recent decades [11-14]. In [11], a miniaturized loop antenna loaded with eight varactor diodes has been discussed to increase the effective bandwidth of the frequency agility. In [14], a varactorloaded frequency reconfigurable split ring resonator antenna has been investigated. The resonance frequency was varied from 365 to $500 \mathrm{MHz}$ whereas the gain was negative in all biased voltages.
On the other hand, the substrate integrated waveguide cavity backed structures that can be fixed to almost any surface without disturbing its characteristics have been widely used on the design of frequency reconfigurable antennas [15-18]. In [15], a quarter-mode SIW cavity antenna employing the capacitive loading tuning method has been proposed. Another SIW cavity backed antenna, which was tuned by pin diodes loaded in four via holes and inserted into the center of the structure, has been developed in [16]. In [17], a frequency agile SIW cavity backed antenna with interdigital capacitor slot has been designed. In [18], a rectangular SIW cavity backed antenna loaded with three varactors has been discussed. A wide tuning range of $0.9 \mathrm{GHz}$ was obtained nevertheless all results of the reflection coefficient was displayed a bad matching level.

The aim of the work presented in this paper is to design and fabricate a low-profile SIW cavity backed antenna with a wide frequency range, high gain and stable radiation patterns. The antenna can be continuously tuned by changing the $\mathrm{DC}$ bias of the two varactors connected across a radiating slot that is circular in shape. Such design covers a frequency range starting from $1.8 \mathrm{GHz}$ to $2.18 \mathrm{GHz}$, which includes the GSM1800, the LTE, and the UMTS wireless standard bands. The simulation results show a good agreement with the measured data and prove the good radiation performance of the proposed frequency agile slotted SIW antenna.

\section{Antenna Design}

The geometry of the reported SIW cavity backed antenna labeled with its dimensions is presented in Fig. 1. It consists of a rectangular SIW cavity powered by a grounded coplanar transmission line and attached to a $50 \Omega$ microstrip line. Two transverse stubs are added to the feeding line in order to increase the coupling efficiency and control the resonant frequency [19]. Besides, a narrow circular radiating slot is carved in the center of the cavity. The layout is printed on a metalized Rogers's substrate with a permittivity of 3.66 , a loss tangent of 0.0031 and a thickness of $1.52 \mathrm{~mm}$. The cavity operates in the transverse 


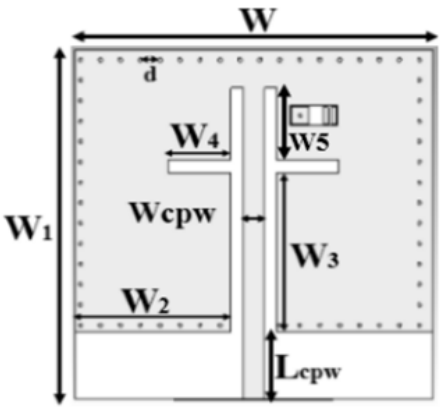

(a)

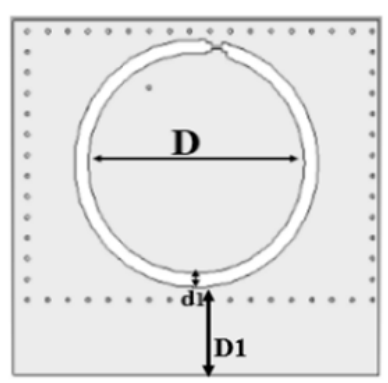

(b)
Fig. 1. Layout of the SIW cavity antenna with circle slot (a) top view; (b) bottom view.

\begin{tabular}{|l|l|l|l|l|l|l|}
\hline Parameters & W & W1 & W2 & W3 & W4 & W5 \\
\hline Value $(\mathrm{mm})$ & 53.9 & 41.4 & 23.5 & 23.4 & 9.4 & 10.5 \\
\hline Parameters & Wcpw & d & Lcpw & D & d 1 & D1 \\
\hline Value $(\mathrm{mm})$ & 3.1 & 2.4 & 10 & 16 & 2 & 13.2 \\
\hline
\end{tabular}

Tab. 1. Dimension parameters of the designed antenna ( $\mathrm{mm})$.

electric fundamental mode $\mathrm{TE}_{101}$. The relation between the operation frequency and the length $L_{\mathrm{c}}$ and width $W_{\mathrm{c}}$ of the cavity can be exhibited from the relations (1), (2) and (3) given in [20].

$$
\begin{gathered}
f_{\text {mnp }}=\frac{1}{2 \sqrt{\mu_{\mathrm{r}} \varepsilon_{\mathrm{r}}}} \sqrt{\left(\frac{m}{L_{\text {eff }}}\right)^{2}+\left(\frac{n}{W_{\text {eff }}}\right)^{2}+\left(\frac{p}{h}\right)^{2}}, \\
L_{\text {eff }}=L_{\mathrm{c}}-\frac{1.08 s^{2}}{d}+\frac{0.1 s^{2}}{L_{\mathrm{c}}}, \\
W_{\text {eff }}=W_{\mathrm{c}}-\frac{1.08 s^{2}}{d}+\frac{0.1 s^{2}}{W_{\mathrm{c}}}
\end{gathered}
$$

where $m, n$, and $p$ are integers.

In fact, the dimensions of the SIW via walls consisting on the diameters of the vias and the spacing between each consecutive ones is optimized by formulas (4) and (5)

$$
\begin{gathered}
d<\lambda_{\mathrm{g}} / 5, \\
s \leq 2 d .
\end{gathered}
$$

The dimensions of the cavity and the radiating slot are obtained by performing different optimization steps to select the desired operation frequency and to achieve a compact design. Table 1 summarizes the final geometric values of the fabricated prototype.

The circular radiation slot is loaded two SMV1430040LF varactors used to control the distribution of the surface current in the antenna and therefore, a continuous frequency tuning can be performed by varying the capacitance value $C$ of the varactors. To facilitate the soldering process of the diodes, a reduction on the radiation slot width is made since that the two varactors have a smaller width as revealed in Fig. 2. Before this step, we discussed the location of the diodes by studying the electrical field distribution as shown in Fig. 3. It is known that a large range of agility can be achieved when the diodes are placed at a location where the field strength is highest.
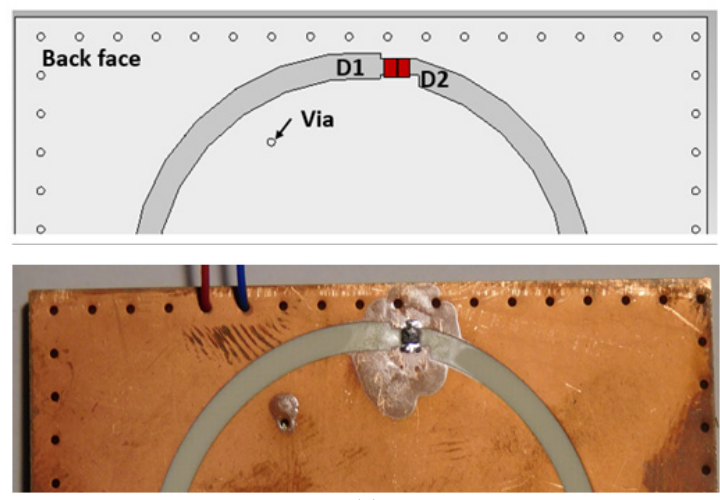

(a)
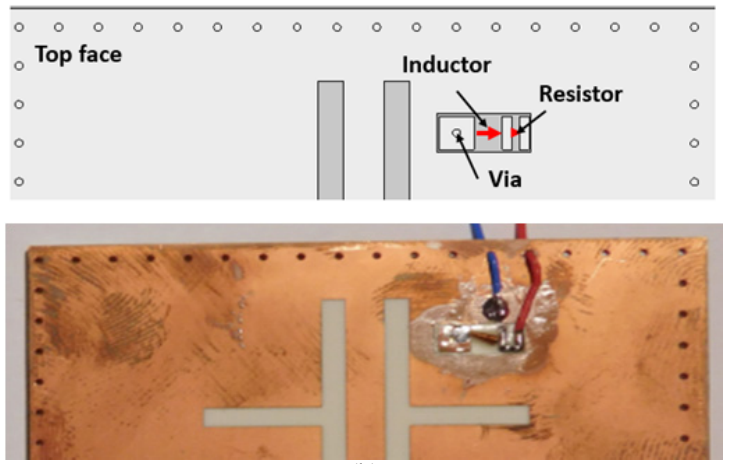

(b)

Fig. 2. Position of the varactor diodes D1 and D2 and the bias voltage network. (a) Bottom face, (b) top face.

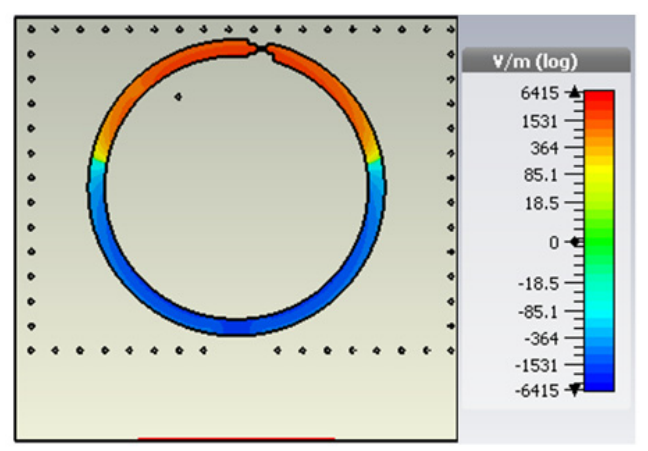

Fig. 3. Electric field distribution of the low profile frequency reconfigurable SIW cavity backed antenna (at the radiation slot) at the resonance frequency $2.28 \mathrm{GHz}$.

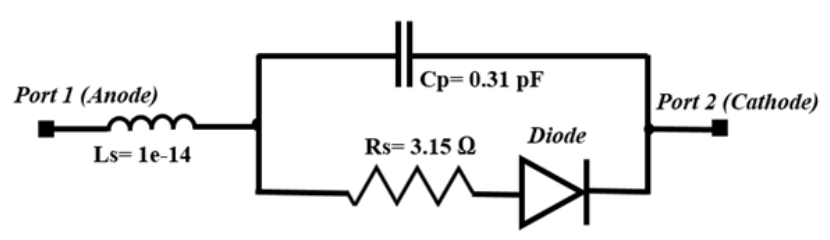

Fig. 4. Equivalent model of the SMV1430-040LF varactor diode.

The equivalent circuit of the diode is shown in Fig. 4. The capacitance of the used diodes is adjustable which means that it can be changed from $0.31 \mathrm{pF}$ to $1.29 \mathrm{pF}(0.31$, $0.43,0.56,0.75,0.91$ and $1.29 \mathrm{pF})$ by varying the bias voltages from 0 to $26 \mathrm{~V}(0,1,2,5,10$ and $26 \mathrm{~V})$, respectively. For the bias circuit, a metalized via is used to connect the insulated central part of the delimited antenna and the insulator patch designed on the upper surface of the 
SIW structure. In addition, an inductor and a resistor are placed between the insulating patches (see Fig. 2(b)). The resistor of $20 \mathrm{k} \Omega$ is acting as a current limiting. The RF chock inductance of type CC45T47K240G5 is having a value of $0.84 \mu \mathrm{H}$. Their roles are respectively to protect the diodes and to isolate the signal.

\section{Experimental Results and Discus- sion}

The full wave simulation of the SIW cavity backed antenna with a circular slot is achieved by CST simulator. The simulation of the antenna without the SMV1430 varactor diode is displayed in Fig. 5. The reflection coefficient is valued at about $-33 \mathrm{~dB}$ at the desired resonant frequency of $2.284 \mathrm{GHz}$. The bandwidth of the reflection coefficient at $-10 \mathrm{~dB}$ is approximately $0.1 \mathrm{GHz}$, which is quite narrow. Also, a prototype was fabricated. The measured results agree very well with the simulated characteristics. Figure 6 presents the simulated result of the 3-D gain and directivity of the proposed antenna without varactor at the resonance frequency $2.284 \mathrm{GHz}$. It can be noted that the antenna has a circular omnidirectional radiation pattern with a maximum gain of $3.21 \mathrm{dBi}$ and a directivity of $4.98 \mathrm{dBi}$, also it can be concluded that a good radiation efficiency of $64 \%$ is achieved.

The frequency reconfigurable antenna was also simulated by the electromagnetic software CST v16. The two varactors were modeled by a parallel RLC circuit, as shown

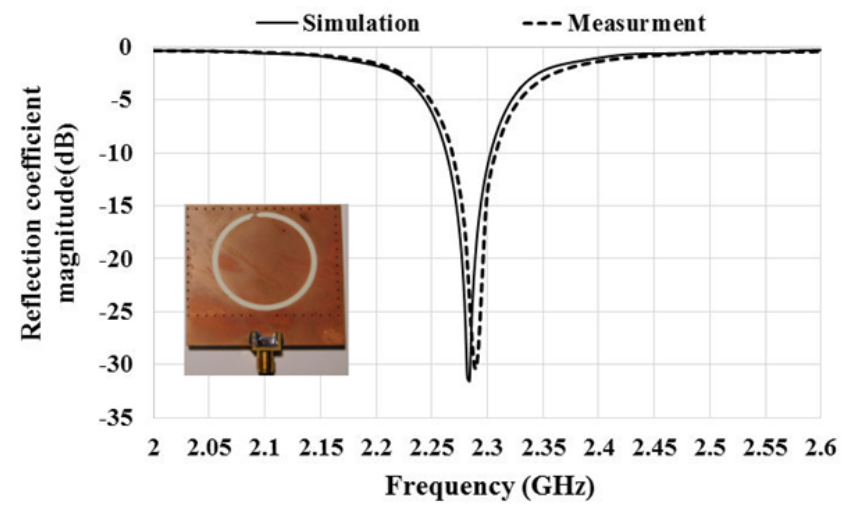

Fig. 5. Measured and simulated results at the operation frequency of the antenna without varactor diodes.

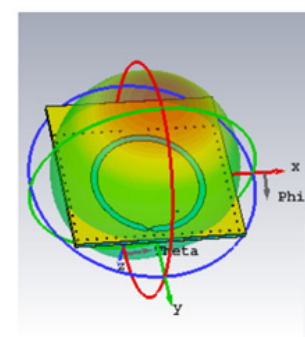

(a)

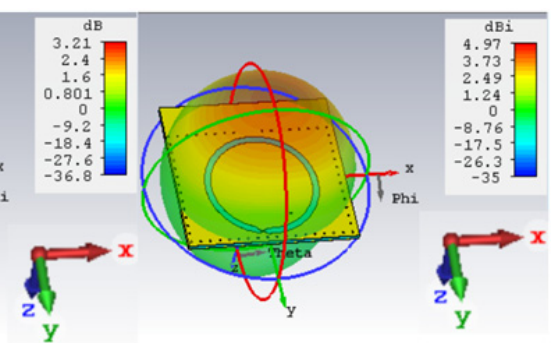

(b)
Fig. 6. Simulated 3-D Gain and directivity of the proposed low profile frequency tunable SIW cavity backed antenna: (a) gain, (b) directivity.
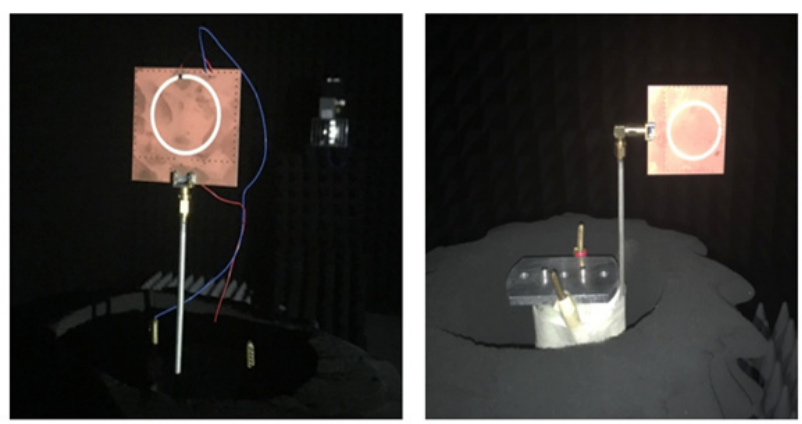

Fig. 7. Photograph of the fabricated antenna during the radiation measurement in the anechoic chamber.

in Fig. 4, and the antenna was fabricated. Figure 7 shows the photograph of the antenna in the anechoic chamber during the measurement process of the radiation performances with and without the varactors in the E- (y-z axis) and $\mathrm{H}$ - plane ( $\mathrm{x}-\mathrm{Z}$ axis).

The measured S11 of the manufactured prototype were figured out through a Rohde \& Schwarz ZVA67 vector network analyzer. Figure 8 compares the magnitude reflection coefficient results of the measurement and the CST simulation. As it can be seen, the antenna performs a tuning range of $1.8-2.18 \mathrm{GHz}$ within the DC bias voltage 0-26 V (0.31-1.29 pF). A satisfactory agreement between the measured and simulated resonant frequencies is observed. However, the experiment shows that the matching levels of the measured values of S11 are higher than those of the simulation. The problem is caused by the influence of diodes and their feeding network. They are not matched to the radiating element. This mismatch can be estimated by comparing plots in Fig. 5 and Fig. 8. Figure 5 shows a good fit of measured S11 with simulation. Figure 8 shows the dependence of simulated $\mathrm{S} 11$ for $1.29 \mathrm{pF}$ that corresponds to zero bias voltage. This can be well compared with those in Fig. 5, of course except frequency. From this we can conclude that measured high reflection is caused by the influence of diodes and their feeding network.

The E- and H-plane radiation patterns of the reconfigurable antenna presented in Fig. 9 are measured for different

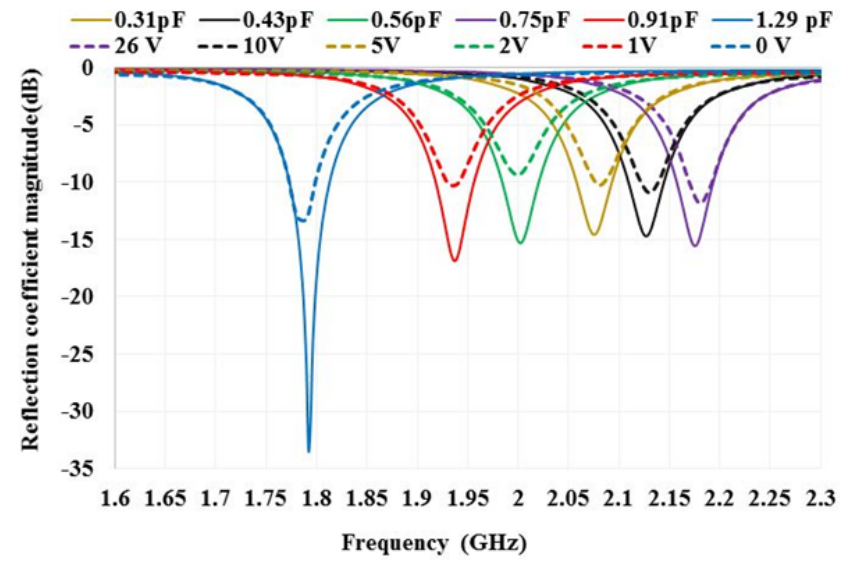

Fig. 8. Simulated (solid lines) and measured (dashed lines) reflection coefficient magnitude of the proposed antenna with the variation of the two varactors capacitancies from 0.31 to $1.29 \mathrm{pF}(0-26 \mathrm{~V})$. 


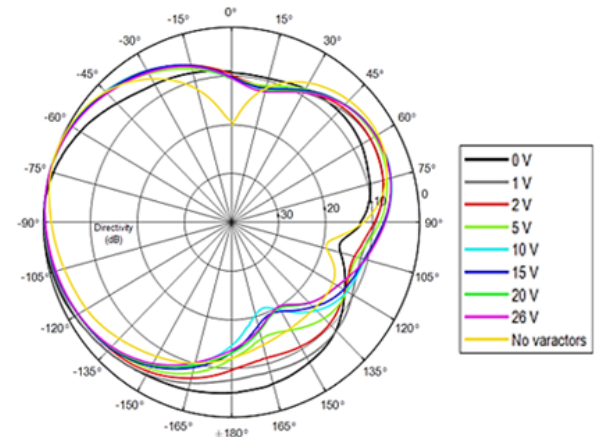

(a)

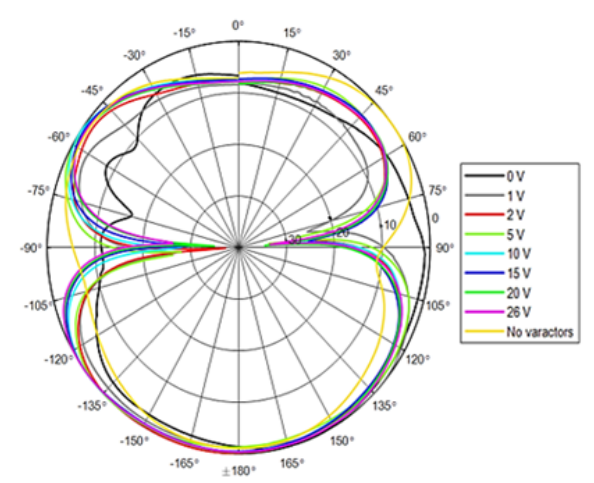

(b)

Fig. 9. Measured (a) E- patterns (y-z plane) and (b) H- patterns (x-z plane) of the fabricated antenna. The reversed bias voltage is changed from $0 \mathrm{~V}$ to $26 \mathrm{~V}$.

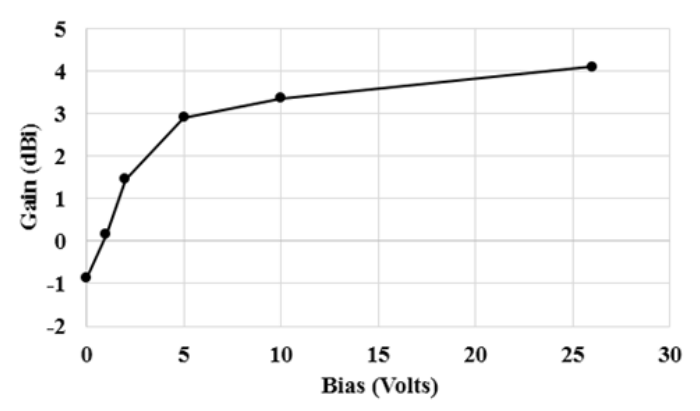

Fig. 10. Measured gain over bias voltages.

\begin{tabular}{|c|c|c|c|c|c|c|}
\hline & {$[\mathbf{1 7 ]}$} & {$[\mathbf{1 8}]$} & {$[\mathbf{1 0 ]}$} & {$[\mathbf{2 1 ]}$} & {$[\mathbf{2 2 ]}$} & $\begin{array}{c}\text { This } \\
\text { work }\end{array}$ \\
\hline $\begin{array}{c}\mathbf{F}_{\max } / \mathbf{F}_{\min } \\
(\mathbf{G H z})\end{array}$ & 1.09 & 1.09 & 1.08 & 1.13 & 1.2 & 1.22 \\
\hline $\begin{array}{c}\mathbf{S}_{11 \max } \\
(\mathbf{d B})\end{array}$ & -18 & -5.59 & -20 & -6 & -7 & -9.5 \\
\hline $\begin{array}{c}\text { No. of } \\
\text { Varactor }\end{array}$ & 1 & 3 & 1 & 1 & 2 & 2 \\
\hline $\begin{array}{c}\text { Gain } \\
\text { (dBax }\end{array}$ & 4 & 4.12 & 0.6 & -2.95 & 3.45 & 4.14 \\
\hline
\end{tabular}

Tab. 2. Comparison of frequency reconfigurable SIW cavity backed antennas presented in literature.

bias voltages (from 0 to $26 \mathrm{~V}$ ). It is clearly noted that at all E- plane patterns, a similar broadside radiation characteristics is obtained.

The measured maximum gain over the varactors bias voltages is presented in Fig. 10. It can be noticed that the gain is increased as the bias voltage increased and therefore the capacitance of the diodes decreased. The peak gain of
$4.1 \mathrm{dBi}$ is obtained at $26 \mathrm{~V}$ whereas it is degraded to $-1 \mathrm{dBi}$ at $0 \mathrm{~V}$.

The performance of the frequency reconfigurable antenna is compared with that of previous works [17], [18], [21], [22] and [23] presented in the literature, as shown in Tab. 2. It is clear that the proposed design has the wide continuous tuning range compared to all the works and the highest gain value.

\section{Conclusion}

This paper presents the design and measurements of a low-profile SIW antenna which radiates through a circular slot etched in the top metallization. The antenna's resonant frequency can be set in the interval between 1.8 to $2.18 \mathrm{GHz}$ by changing the DC bias of the two varactors from 0 to $26 \mathrm{~V}$. Both the simulation and experiment results indicate that the frequency adjustment range is approximately $380 \mathrm{MHz}$. In addition, only a small modification of the antenna radiation pattern has been observed in the process of tuning, which is a required radiation performance for many practical applications as in wireless communication systems such as the GSM1800, the LTE, and the UMTS standards.

\section{Acknowledgments}

This work was supported by the Grant Agency of the Czech Republic under Project 17-00607S.

\section{References}

[1] GUNDUMAlla, A., AGRAWAL, S., PARIHAR, M. S. Compact planar active integrated inverted-F antenna with frequency reconfigurable capability. IET Microwaves, Antennas \& Propagation, 2018, vol. 12, no. 13, p. 2012-2018. DOI: 10.1049/iet-map.2018.5236

[2] CHUNG, K. L., XIE, S., LI, Y., et al. A circular-polarization reconfigurable Meng-shaped patch antenna. IEEE Access, 2018, vol. 6, p. 51419-51428. DOI: 10.1109/ACCESS.2018.2869410

[3] BOUKARKAR, A., LIN, X. Q., JIANG, Y., et al. Compact mechanically frequency and pattern reconfigurable patch antenna. IET Microwaves, Antennas \& Propagation, 2018, vol. 12, no. 11, p. 1864-1869. DOI: 10.1049/iet-map.2017.0917

[4] WU, R. X., TAN, L. R., LOU, Q. Reconfigurable ferrite-loaded SIW antenna. In 2015 Asia-Pacific Microwave Conference (APMC). Nanjing (China), 2015, vol. 2, p. 1-3. DOI: 10.1109/APMC.2015.7413098

[5] TAN, L. R., WU, R. X., POO, Y. Magnetically reconfigurable SIW antenna with tunable frequencies and polarizations. IEEE Transactions on Antennas and Propagation, 2015, vol. 63, no. 6, p. 2772-2776. DOI: 10.1109/TAP.2015.2414446

[6] MAZLOUMAN, S. J., JIANG, X. J., MAHANFAR, A., et al. A reconfigurable patch antenna using liquid metal embedded in a silicone substrate. IEEE Transactions on Antennas and Propagation, 2011, vol. 59, no. 12, p. 4406-4412. DOI: 10.1109/TAP.2011.2165501 
[7] VERMA, A., PARIHAR, M. S. Multifunctional antenna with reconfigurable ultra-wide band characteristics. Radioengineering, 2017, vol. 26, no. 3, p. 647-654. DOI: 10.13164/re.2017.0647

[8] BARBUTO, M., BILOTTI, F., TOSCANO, A. Design of a multifunctional SRR-loaded printed monopole antenna. International Journal of RF and Microwave Computer-Aided Engineering, 2012, vol. 22, no. 4, p. 552-557. DOI: $10.1002 /$ mmce. 20645

[9] TOPALli, K., ERDIL, E., CIVI, O. A., et al. Tunable dualfrequency RF MEMS rectangular slot ring antenna. Sensors and Actuators A: Physical, 2009, vol. 156, no. 2, p. 373-380. DOI: 10.1016/j.sna.2009.10.005

[10] BEHDAD, N., SARABANDI, K. A varactor-tuned dual-band slot antenna. IEEE Transactions on Antennas and Propagation, 2006, vol. 54, no. 2, p. 401-408. DOI: 10.1109/TAP.2005.863373

[11] CHI, P. L., WATERHOUSE, R., ITOH, T. Compact and tunable slot-loop antenna. IEEE Transactions on Antennas and Propagation, 2011, vol. 59, no. 4, p. 1394-1397. DOI: 10.1109/TAP.2011.2109687

[12] HUANG, H. J., LAI C. P., CHEN, S. Y. Miniaturized CPW-fed slot loop antenna with frequency agility. In IEEE Antennas and Propagation Society International Symposium (APSURSI). Memphis (TN, USA), 2014, p. 283-284. DOI: 10.1109/APS.2014.6904473

[13] HUSSAIN, R., GHALIB, A., SHARAWI, M. S. Annular slotbased miniaturized frequency agile MIMO antenna system. IEEE Antennas and Wireless Propagation Letters, 2017, vol. 16, p. 2489-2492. DOI: 10.1109/LAWP.2017.2726058

[14] ZHU, S., HOLTBY, D. G., FORD, K. L., et al. Compact low frequency varactor loaded tunable SRR antenna. IEEE Transactions on Antennas and Propagation, 2013, vol. 61, no. 4, p. 2301-2304. DOI: 10.1109/TAP.2013.2239952

[15] SAGHATI A. P., ENTESARI, K. A tunable quarter-mode substrate integrated waveguide antenna. In 2016 IEEE International Symposium on Antennas and Propagation (APSURSI). Fajardo (Puerto Rico), 2016, p. 841-842. DOI: 10.1109/APS.2016.7696129

[16] SAGHATI A. P., ENTESARI, K. A reconfigurable SIW cavity backed slot antenna with one octave tuning range. IEEE Transactions on Antennas and Propagation, 2013, vol. 61, no. 8, p. 3937-3945. DOI: 10.1109/TAP.2013.2263215

[17] SAM, S., KANG, H., LIM, S. Frequency reconfigurable and miniaturized substrate integrated waveguide interdigital capacitor (SIW-IDC) antenna. IEEE Transactions on Antennas and Propagation, 2014, vol. 62, no. 3, p. 1039-1045. DOI: 10.1109/TAP.2013.2281662

[18] SBOUI, F., MACHAC, J., GHARSALLAH, A. Tunable slot antenna backed by substrate integrated waveguide cavity. International Journal of $R F$ and Microwave Computer-Aided Engineering, 2018, vol. 28, no. 9, p. 1-6. DOI: $10.1002 /$ mmce. 21591

[19] PORTILLA, R. D. X-band substrate integrated waveguide cavitybacked patch antenna self-oscillating mixer. Thesis. Universitat Politècnica de Catalunya, Spain, 2010.

[20] ENTESARI, K., SAGHATI, A. P., SEKAR, V. et al. Tunable SIW structures: Antennas, VCOs, and filters. IEEE Microwave
Magazine, 2015, vol. 16, no. 5, p. 34-54. DOI: 10.1109/MMM.2015.2408273

[21] ZHAO, Y., ZHANG, Z., FENG, Z. A dual-band tunable ultra-thin cavity antenna. IEEE Antennas and Propagation Letters, 2011, vol. 10, p. 717-720. DOI: 10.1109/LAWP.2011.2161745

[22] CHENG, Y. J. Substrate integrated waveguide frequency-agile slot antenna and its multibeam application. Progress in Electromagnetics Research, 2012, vol. 130, p. 153-168. DOI: 10.2528/PIER12061602

[23] http://datasheet.octopart.com/SMV1405-040LF-SkyworksSolutions-datasheet-11039839.pdf.

\section{About the Authors...}

Fakher SBOUI was born in El Hamma Gabes, Tunisia. He received the master degree in Electrical Engineering from the Faculty of Sciences of Tunis, Tunisia in 2015. He is currently working toward the Ph.D. degree in Electrical Engineering at the same faculty. His main research interests lie in the reconfigurable antennas design and the SIW technology.

Jan MACHAC was born in Hranice, Czechoslovakia, in 1953. He graduated from the CTU in Prague in 1977. He received his CSc. (Ph.D. equivalent) in Electronics in 1982 at the Institution of Radio Engineering and Electronics of the Czechoslovak Academy of Science in Prague. He received his DrSc. degree in Radio Electronics in 1996 and was named a professor of Electrical Engineering in 2009. His main scientific interests cover investigation of planar passive elements and subsystems of microwave technology, propagation of electromagnetic waves in periodic structures and metamaterials. He is the author or co-author of more than 250 publications in scientific journals, including international ones as well as national conferences.

Ali GHARSALLAH received the degree in Radio Frequency Engineering from the Higher School of Telecommunication of Tunis in 1986 and the Ph.D. degree in 1994 from the Engineering School of Tunis. Since 1991, he has been with the Department of Physics at the Faculty of Sciences of Tunis. Actually, he is a full Professor in Electrical Engineering and the Director of the Engineering studies in the Ministry of Higher Education of Tunisia. His current research interests include smart antennas, array signal processing, multilayered structures and microwave integrated circuits. He has about eighty papers published in scientific journals and more than a hundred conference papers. Professor Gharsallah supervises more than twenty thesis and fifty Masters. 